\title{
Perceived Paternal Parenting Style and Proactive Coping Strategies of Indian Adolescents
}

\author{
Pratishtha Bhattacharyya ${ }^{1} \&$ Rabindra Kumar Pradhan ${ }^{1}$ \\ ${ }^{1}$ Department of Humanities and Social Sciences, Indian Institute of Kharagpur, West Bengal, India \\ Correspondence: Rabindra Kumar Pradhan, Department of Humanities and Social Sciences, Indian Institute of \\ Technology Kharagpur, 721302, West Bengal, India. Tel: 91-943-470-3900. E-mail: rabi2020@gmail.com
}

Received: April 1, 2015

Accepted: April 9, 2015

Online Published: May 29, 2015

doi:10.5539/ijps.v7n2p180

URL: http://dx.doi.org/10.5539/ijps.v7n2p180

\begin{abstract}
Parental child rearing practices are regarded as significant step towards development of coping skills in children and adolescents. The role of fathers in child's progress from infancy through adulthood is undeniable. The unique bond that a father and a child share is instrumental in influencing various behavioural outcomes in children. For a traditional country like India the emergence of active involvement of fathers in parenting is increasingly becoming popular. The present study investigates the influence of perceived paternal parenting styles on adolescents' coping strategies. Family structure, gender of adolescents and income of father were taken as moderators in the study. The sample of this study was $\mathrm{N}=180$ (male $45.6 \%$ and female $54.4 \%$ ). Adolescents from standard X-XI, belonging to joint family (22.8\%) and nuclear family (77.2\%) were selected from different schools in Kharagpur, West Bengal (India). Analysis of variance and hierarchical multiple regression analysis were carried out for data analysis. Results revealed that adolescents' perception of paternal demandingness and autonomy granting significantly predicts preventive and instrumental coping strategies among adolescents. Income of father and gender of adolescent were found to moderate the relationship between perceived paternal parenting style and coping strategies.
\end{abstract}

Keywords: adolescents, proactive coping strategies, family structure, income of father, paternal parenting styles

\section{Introduction}

The changing face of Indian parenting with its unique assimilation of traditional and new is promising when it comes to children's capacity development. The present day globalized society has provided a new platform to bring forth a mix of old eastern and western concepts in the area of parenting. For a traditional country like India the emergence of active involvement of fathers in parenting is increasingly becoming popular. Indian fathers are generally portrayed as authoritarian (Kakar, 1978). Nevertheless, recent researches suggest that middle-class fathers in urban India are increasingly becoming actively involved in their children's lives (Roopnarine, Talukder, Jain, Joshi, \& Srivastav, 1990). Paternal involvement not only suggests a promising cultural shift in the parenting concepts of Indian fathers; but child outcomes as well. Contemporary investigations on Indian paternal parenting show significant influence on child outcomes; such as social competence (De Souza \& Paul, 2013), academic achievement (Lakshmi \& Arora, 2006), emotional intelligence (Shalini \& Balakrishna, 2013), anxiety (Thergaonkar \& Wadekar, 2007), Depression (M. Sharma, Sharma, \& Yadava, 2011) and coping with emotion and stress (Bhat \& Aminabhavi, 2011). However, literature specifically exploring the relationship of Indian paternal parenting style and specific coping strategies are rare.

\subsection{Cultural Context in Parenting}

Chao (1994), Darling and Steinberg (1993) have argued that child outcomes prompted by parenting style may be the result of differences in social environment, the cultural meaning of specific dimensions of parenting practices and parent-child interaction. The sense of being controlled or manipulated by parents in one may be associated with feelings of love and concern in a different culture (Mason, Walker-Barnes, Tu, Simons, \& Martinez-Arrue, 2004). Across diverse culture the different communicative transactions that parents have with their children has given rise to a collective outlook towards child rearing. The parenting practices or specific behaviours when put under one comprehensive umbrella becomes parenting style (Spera, 2005).Darling and Steinberg (1993) regard the concept of parenting style as conglomeration of parental attitudes expressed towards children. 
Darling and Toyokawa (1997) developed three subscales to assess the three dimensions of maternal parenting style: demandingness, emotional responsiveness, and psychological autonomy-granting. Autonomy is referred to as self-initiation and self-regulation of one's own actions (Deci, Vallerand, Pelletier, \& Ryan, 1991). Baumrind (1991) refers to demandingness construct as the parent's willingness to involve the child in to the family as a whole guided by their supervision, disciplinary effort and willingness to resist disobedience from children. On the other hand, Responsiveness is parental recognition of and child's individual existence (Baumrind, 1991).

The central theme in case of an Asian parenting is family and family interdependence (Chao \& Tseng, 2002). The striking distinction between South Asian families and East Asian families is the concept of interdependence, which traditional Indian families practice in vogue (Chao \& Tseng, 2002; Jambunathan \& Counselman, 2002). The presence of extended family in an Indian family environment results in diminished autonomy for the child and increased parental control (Rose, Dalakas, \& Kropp, 2003). It has been found that the concept of autonomy is influenced as much by culture as by parenting (Manzi, Regalia, Pelucchi, \& Fincham, 2012).

\subsection{Coping and Parenting Style}

Coping is defined as "constantly changing cognitive and behavioural efforts to manage specific external and/or internal demands that are appraised as taxing or exceeding the resources of the person" (Lazarus \& Folkman, 1984). We observe developmental trends in the materialization of various coping strategies (Compas et al., 1991). Positive relationship with parents is found to act as type of social support, thereby enhancing psychological resources. Increased social support helps the adolescents in turn to cope with stressful events (Cohen \& Wills, 1985; Baumrind, 1991).The present study hence attempts to investigate the relationship between paternal parenting style and coping strategies.

Every parenting style is unique in its own way, and each of it has a different relationship with various child and adolescent behavioural outcomes, such as coping. Parenting styles are found to have direct relationship with coping strategies (Lin \& Lian, 2011). Controlling parenting styles are found to closely relate to psychological disturbance in adolescence (Dusek \& Danko, 1994). Whereas autonomy granting parenting is found to contribute to lower levels of behaviour problems, healthy psychosocial wellbeing and development and increased academic achievement (Gray \& Steinberg, 1999). Paternal warmth on the other hand was found to correlate significantly with active coping styles (Wolfdrat, Hempel, \& Miles, 2003).

\subsection{The Moderating Role of Gender of Adolescents, Income, and Family Structure}

Previous investigations on Indian parenting style also focuses on the requirement to study background information like; parents' age, educational level, socio-economic status, and family size as potential factors influencing parenting (Akhtar, 2012). In addition, this study also addresses another gap in literature that is, the role of moderators in determining the relationship paternal parenting style and coping strategies. Western literature on parenting style point out quite a few number of variables to be potential moderators and mediators such as temperament, gender of adolescents, socioeconomic status and ethnicity of parents, the child's age, and family structure (Terry, 2004). The present study considers the role of three moderators namely income of father, gender of adolescent, and family structure as significant contributor to the relationship between paternal parenting style and coping strategies.

Socio-economic status of parents too plays a significant role in determining parenting styles. Authoritarian parenting from lower socioeconomic status is found to predict externalizing behaviours among adolescents (Meteyer \& Jenkins, 2009). Investigations indicate that Indian parents from lower socio-economic status might not value other attributes as they would value obedience in their children (Verma \& Sharma, 2006). Galy (2007) examined the moderating effects of important family socio-economic factors such as parents' education, family income and gender on the association between parenting styles, family environment and adolescent wellbeing. Family income was found to significantly moderate the relationship between authoritative parenting and adolescents' self-esteem in Galy's (2007) research rather than age and gender. Certain other studies also point out the significance of parental income; where high income is found to foster supportive parenting styles whereas parenting under low income circumstances shows hindered development of children leading to attention problem, delinquency, and aggression (Barnow et al., 2002).

Family structure is at the core of Indian parenting. With the concept of interdependence that Indian joint families foster or the growing trend of individual atmosphere fostered by the present day urban and suburban nuclear families; family structure is deemed significant while considering child rearing practices in India. Indian children in nuclear families are reported to enjoy greater autonomy in comparison to those growing up in a joint family atmosphere (D'Cruz \& Bharat, 2001). More of authoritarianism is practiced in case of an extended or joint family environment. Joint family requires its members to co-operate according to the authority of the household; 
on the other hand nuclear promotes more individualism (D'Cruz \& Bharat, 2001). It is also reported that most "unhealthy" children come from joint families; because of the constraint that forces living together out of compulsion not choice (Isaac, Annie, \& Prashanth, 2014). But nuclear families also suffer on premises of autonomy provided to children which is at times found to be indistinctly demarcated by parents (Chaddha \& Deb, 2013). Older western researches also points the distinct role of family structure; where it is found to moderate the relation between parenting style and children related outcomes like school achievement (Baron \& Kenny, 1986). A dearth has been felt while exploring related literature on role of family structure as moderators influencing the association of parenting styles and child related outcomes.

The traditional concept of males over females as reported by Dasgupta (1987) by both mother and father is slowly losing its ground in urban and suburban areas in India. Indian Fathers' traditional image of an authoritarian parent to their children (Kakar, 1978) too is being overshadowed with emergence of urban fathers who are responsive, interactive and affectionate (Roopnarine, Talukder, Jain, Joshi, \& Srivastav, 1990). Rai, Pandey and Kumar's (2009) investigation Khasi adolescents revealed a drift from the traditional perception on Indian parenting by gender. Natarajan's (2010) exploration of perceived parenting styles among immigrated India to U.S.A found that females reported parents as more authoritative (higher on responsiveness) than their male counterparts. Khasi males in the study reported more rejection as compared to females; females reported more emotional warmth from fathers. A recent study by Shalini and Balakrishna Acharya (2013) on influence of perceived paternal parenting styles on emotional intelligence of adolescents show; that girls in comparison to boys perceive their fathers to be more authoritative towards them. But contemporary Indian studies hardly show the consideration of gender of adolescent as a significant moderator influencing the association of perceived paternal parenting style and child outcomes. Hence the present study attempts at including gender of adolescent as a moderator between perceived paternal parenting style coping strategies.

Although researches has been conducted to explore the association between parenting style and coping. Very few researches in India focused on investigating parenting styles and their impact on specific coping strategies. The present research attempted to investigate the influence of parenting styles of fathers on proactive coping strategies. Proactive coping refers to efforts taken prior to a stressful event in order to prevent it or to modify its form so as to deter its occurrence (Aspinwall \& Taylor, 1997). Proactive coping comprise of goal setting and tenaciously pursuing the said goal (Kadhiravan \& Kumar, 2012). Schwarzer (2000) points out four types of coping namely; reactive, anticipatory, preventive and proactive coping. The distinction among these four types of coping lies in the concept as how much different the coping types are in terms of creating opportunities, and positive experience instead of mere responses to negative events (Schwarzer \& Taubert, 2002; Schwarzer \& Knoll, 2003). The main purpose of the study was to examine the effect of perceived paternal parenting styles on proactive coping strategies. The second purpose of this study was to examine the moderating role of income of fathers, gender of adolescents and family structure between perceived paternal parenting style and proactive coping strategies.

\section{Method}

\subsection{Sample}

The sample of the study consisted of 204 adolescents initially (16-18 years of age) from three English medium schools from Kharagpur. The study is quasi experimental in nature. The demography of the sample included male $(45.6 \%)$ and female $(54.4 \%)$ adolescents from standard X-XI, of which adolescents from joint family $(22.8 \%)$ and nuclear family $(77.2 \%)$. On the basis of income of parents, adolescents were again divided in two categories; parent's income of above 15 thousand per month to 25 thousand per month (53.3\%) and below 15 thousand per month to 8 thousand per month $(46.7 \%)$. The sample of the study unintentionally included adolescents with only father as the sole earner of the family. A random sampling technique was conducted to extract data. Out of 204 adolescents 180 were extracted (98 female and 82 males) with both parents alive and used for final analysis.

\subsection{Measures}

Proactive Coping Inventory (PCI) was used to measure coping. It consists of 7 subscales (with 55 items. This scale possesses good reliability and validity; the internal consistency of the scale range from .71 to .85 for all 7 scales (Greenglass, Schwarzer, \& Taubert, 1999). Only 3 subscales namely, proactive, preventive, and instrumental coping were used for this present study. Each item is rated on a 4-point Likert scale ranging from 1 to 4 , which is based on the frequency with which individuals agrees with the statements. Here 1signifies "not all true", 2 ("barely true"), 3 ("somewhat true") and 4 is signified as "completely true". 
Parenting Style Inventory II (PSI-II) by Nancy Darling and Teru Toyokawa (1997) was used to measure parenting style. It consists of three subscales showing reliability of demandingness, $=.72$; responsiveness, $=.74$; autonomy-granting, $=.75$ as reported by Darling and Toyokawa (1997). Both father and mother form of the scale is available. Only the father form was used in the present study. Each form has 15 items which is rated on a 5-point Likert scale that ranges from 1 (strongly disagree) to 5 (strongly agree).

Both of the scales were self administered and were filled in by adolescents themselves.

\subsection{Procedure}

Participation in the study was voluntary. For the purposes of this study, only intact or two-parent families were selected. Prior permission was taken from the school authority to conduct the survey. A questionnaire survey was conducted by the researcher in the said schools. Questionnaires in English were distributed in standards X-XI during free periods. The survey took approximately took one hour. As a token of appreciation small food items were distributed to the students. SPSS 20 was used for statistical analysis in the present study.

\section{Results}

\subsection{Preliminary Analysis}

Table 1 provides a descriptive analysis such as mean, standard deviation, skewness and kurtosis for paternal parenting style, income of father, family structure, gender of adolescent, and proactive coping strategies (proactive, preventive, and instrumental). For data to be normally distributed skewness and kurtosis both should fall in the range from +2 to -2 if data are normally distributed (Lewis, Bryman, \& Liao, 2004). The univariate skewness and kurtosis of the variables in the study falls in range for normally distributed data.

Table 1. Means, Standard Deviations, skewness and kurtosis of scores for gender of adolescent, income of father, family structure, proactive coping, preventive coping, instrumental coping, paternal responsiveness, paternal autonomy granting, and paternal demandingness

\begin{tabular}{lllll}
\hline & Mean & Std. Deviation & Skewness & Kurtosis \\
\hline Gender of adolescent & .4556 & .49941 & .180 & -1.990 \\
Family structure & .7722 & .42057 & -1.309 & -.290 \\
Income of father & .0667 & 1.00056 & -.135 & -2.004 \\
Proactive coping & 42.7556 & 4.49782 & -.293 & -.074 \\
Preventive coping & 31.4444 & 4.41205 & -.233 & -.832 \\
Instrumental coping & 23.7556 & 4.37951 & -.119 & -.672 \\
Responsiveness & 15.7000 & 3.13371 & .165 & -.520 \\
Autonomy granting & 14.6333 & 3.11224 & .077 & -.347 \\
Demandingness & 18.7667 & 3.42534 & -.512 & -.019 \\
\hline
\end{tabular}

A review of the descriptive statistics show demandingness style in parenting as perceived by adolescents to leading followed by responsiveness, and autonomy granting style respectively.

Table 2. Zero-order correlations of variables $(\mathrm{N}=180)$

\begin{tabular}{lllllllll}
\hline Variable & 1 & 2 & 3 & 4 & 5 & 6 & 7 & 8 \\
\hline 1.Responsiveness & - & & & & & & & \\
2.Demandingness & .094 & - & & & & & \\
3.Autonomy Granting & $.291^{* * *}$ & $-.140^{* *}$ & - & & & & \\
4.Income of father & .031 & $.197^{* *}$ & .019 & - & & & \\
6.Gender of adolescent & $-.205^{* *}$ & .046 & -.111 & .051 & - & & \\
7.Proactive coping & $.143^{*}$ & .031 & $-.095^{*}$ & -.145 & .013 & - & \\
8. Instrumental coping & .174 & .164 & .249 & $.136^{* *}$ & -.010 & .054 & - \\
9. Preventive coping & .118 & $.193^{* *}$ & .201 & $-.098^{* *}$ & -.070 & .157 & $.540^{* * *}$ & - \\
\hline Note. ${ }^{*} \mathrm{p}<.05 ; * \mathrm{p}<.005 ; * * \mathrm{p}<.001$ & & & & & &
\end{tabular}


Zero order correlation presented in Table 2, show significant positive correlation between paternal responsiveness and proactive coping, demandingness and preventive coping, income of father and instrumental coping. Significant negative correlation is seen between paternal responsiveness and gender of adolescent, paternal autonomy granting and gender of adolescent, proactive coping; and between income of father and preventive coping.

A multivariate analysis of variance (MANOVA) was also conducted to examine whether three paternal parenting styles (responsiveness, autonomy granting, and demandingness) varied as a function of income father, gender of adolescent and family structure. Results revealed no significant main effect. But the factorial MANOVA revealed a significant multivariate two way interaction effect for family structure $\mathrm{x}$ gender of adolescent, Wilks' $\lambda=.914, \mathrm{~F}(3,170)=5.3, \mathrm{p}<.01$, partial eta squared $=.086$. Power to detect the effect was .928 . Given the significance of the overall test, the univariate main effects were examined. Significant univariate interaction effects for family structure $\mathrm{x}$ gender of adolescent were obtained for paternal responsiveness, $\mathrm{F}(3,170)=13.10$, $\mathrm{p}<.001$, partial eta square $=.071$, power $=.949$.

Also a significant multivariate two way interaction effect for gender of adolescent $\mathrm{x}$ income of father was revealed; where Wilks' $\lambda=.948, \mathrm{~F}(3,170)=3.08, \mathrm{p}<.05$, partial eta squared $=.052$. Power to detect the effect was .713. Given the significance of the overall test, the univariate main effects were examined. Significant univariate interaction effects for gender of adolescent $\mathrm{x}$ income of father were obtained for paternal responsiveness, $\mathrm{F}(3,170)=6.7, \mathrm{p}<.01$, partial eta square $=.037$, power $=.730$. A Significant univariate interaction effects for gender of adolescent income of father were obtained for paternal autonomy granting, $\mathrm{F}$ $(3,170)=4.7, \mathrm{p}<.05$, partial eta square $=.027$, power $=.577$.

A third a significant multivariate three way interaction effect for family structure $\mathrm{x}$ gender of adolescent $\mathrm{x}$ income of father was obtained; where Wilks' $\lambda=.922, \mathrm{~F}(3,170)=4.8, \mathrm{p}<.01$, partial eta squared $=.078$. Power to detect the effect was .713. Given the significance of the overall test, the univariate main effects were examined. Significant univariate interaction effects for family structure $\mathrm{x}$ gender of adolescent $\mathrm{x}$ income of father were obtained for paternal autonomy granting, $\mathrm{F}(3,170)=9.2, \mathrm{p}<.01$, partial eta square $=.051$, power $=.856$.

\subsection{Analyses of Moderator Variables in the Study}

Prior analyses were conducted to ensure no violation of the assumptions of normality, linearity, and homoscedasticity was graphically tested using a plot of standardized residuals against standardized predicted values (Field, 2013). Multicollinearity was checked with tolerance and VIF; Durbin-Watson test was conducted to check independence of errors (Field, 2013). For interaction testing, variables were centered in order to avoid multicollinearity (Aiken \& West, 1991). Centered score was obtained by subtracting the mean from the original independent variable score (Afshartous \& Richard, 2011). Demographic factors were dummy coded in the following way: family structure (joint $=0$, nuclear family $=1$ ), gender of adolescent (male $=1$, female $=0$ ), Income of father (Above 15 thousand $=1$, below 15 thousand $=-1$ ).

Each moderator had five parallel hierarchical multiple regression analyses, one for each coping strategies namely (proactive, reflective, strategic, preventive and instrumental) as dependent variable. Income of father, gender of adolescent and family structure was tested for moderation. For each hierarchical regression, perceived parenting styles were entered as a covariate in Step 1; the moderator was entered in step 2 to test the main effect (Keshavarz \& Baharudin, 2012). Two way interaction term of each parenting style parenting style $\mathrm{x}$ the moderator was created in step 3. Further the $p$ value criterion of the present study was set at .01 to evaluate the contribution of interaction effect. Wei et al. (2008) state that the contribution of an interaction effect in a hierarchical regression is generally quite small, hence a liberal criterion is recommended.

The first step of hierarchical multiple regression for every subsequent regression conducted in the present study yielded similar results. In Step 1, three predictors were entered: paternal responsiveness, paternal demandingness, and paternal autonomy granting parenting style were entered. In Table 3, the step 1, of hierarchical multiple regressions for proactive coping indicate that paternal responsiveness accounted for $4 \%$ of the variance in proactive coping strategy. Perceived paternal responsiveness and proactive coping strategy was found to associate at a low level of significance $(\beta=.202, \mathrm{p}<.05)$.The step 1 , of hierarchical multiple regression for preventive coping indicate that paternal demandingness and autonomy granting accounted for $9 \%$ of the variance in preventive coping strategy. Results presented in Table 3, Paternal demandingness was found to positively predict preventive coping strategy $(\beta=.221, \mathrm{p}<.01)$; besides paternal autonomy granting too was found to positively predict preventive coping strategy $(\beta=.222, \mathrm{p}<.01)$. A little further as indicated in Table 3 , step 1 of the hierarchical multiple regression for instrumental coping show; paternal demandingness and autonomy 
granting accounted for $11 \%$ of the variance in instrumental coping strategy. As presented in Table 3, Paternal demandingness was found to positively predict instrumental coping strategy $(\beta=.191, p<.01)$; in addition paternal autonomy granting too was found to positively predict instrumental coping strategy $(\beta=.252, p<.001)$. The first purpose of the study to examine the effect of perceived paternal parenting style on proactive coping strategies was achieved with this step. In a nut shell, results of regression point out that; adolescents' perception of paternal demandingness and autonomy granting predicts preventive and instrumental strategies in adolescents, and paternal responsiveness was found to predict proactive coping strategy in adolescents.

\subsubsection{Income of Father}

Results provided in Table 3, presents the moderator effect of income of father for three coping strategies (proactive, preventive, and instrumental) respectively. The interaction effect entered at step 3 , of each the separate hierarchical multiple regressions for three coping strategies show the moderator effect.

In step 2, of hierarchical regression for proactive coping shows that, income of father accounted for $6 \%$ of the variance in proactive coping. Step 3, shows that the interaction of income of father with three parenting styles (responsiveness, demandingness, and autonomy granting) respectively accounted for $11 \%$ of variance in proactive coping strategy. No significant interaction effect of income of father with each of the three paternal parenting styles (responsiveness, demandingness, and autonomy granting) was observed in the analysis.

In step 2, of hierarchical regression for preventive coping shows that, income of father accounted for $11 \%$ of the variance in preventive coping. Income of father negatively predicted preventive coping strategy $(\beta=-.153, p$ $<.05)$. The results of step 2, reveals that with every one unit increase in income of father above 15 thousand there is a 1.21 unit decrease in preventive coping strategy. Step 3, shows that the interaction effect of income of father with three parenting styles (responsiveness demandingness, and autonomy granting) respectively accounted for $17 \%$ of variance in preventive coping strategy. A significant interaction effect of parental demandingness $\mathrm{x}$ income of father was noticed $(\beta=-.213, \mathrm{p}<.01)$. The contribution of income of father is most in the second step as revealed from the $\mathrm{sr}^{2}=.216$. Two explore the interaction effect more interaction plot was formed with the help of Modgraph-I (Jose, 2013). The interaction effect in Figure 1, conveys, that high paternal demandingness is moderately associated with preventive coping strategy for adolescents with income of father below15 thousand than income of father above 15 thousand (Simple Slopes for the comparison group: Below 15 $=0.248, \mathrm{p}<.05$; Simple Slope for the dummy coded group: Above $15=-0.027, \mathrm{p}>.05$ ).

In step 2, of hierarchical regression for instrumental coping shows that, income of father accounted for $11 \%$ of the variance in instrumental coping. Step 3, shows that the interaction of income of father with three parenting styles (responsiveness demandingness, and autonomy granting) respectively accounted for $15 \%$ of variance in in instrumental coping strategy. No significant interaction effect of income of father with each of the three paternal parenting styles (responsiveness, demandingness, and autonomy granting) was observed in the analysis.

\subsubsection{Gender of Adolescent}

Results provided in Table 5, presents the moderator effect of gender of adolescent for three coping strategies (proactive, preventive, and instrumental) respectively. The interaction effect entered at step 3 , of each the separate hierarchical multiple regressions for three coping strategies show the moderator effect.

In step 2, of hierarchical regression for proactive coping shows that, gender of adolescent accounted for $4 \%$ of the variance in proactive coping. Step 3, shows that the interaction of gender of adolescent with three parenting styles (responsiveness demandingness, and autonomy granting) respectively accounted for $9 \%$ of variance in proactive coping strategy. No significant interaction effect of with gender of adolescent each of the three paternal parenting styles (responsiveness, demandingness, and autonomy granting) was observed in the analysis.

In step 2, of hierarchical regression for preventive coping shows that, gender of adolescent accounted for $9 \%$ of the variance in preventive coping. Step 3, shows that the interaction of gender of adolescent with three parenting styles (responsiveness, demandingness, and autonomy granting) respectively accounted for $13 \%$ of variance in preventive coping strategy. No significant interaction effect of with gender of adolescent each of the three paternal parenting styles (responsiveness, demandingness, and autonomy granting) was observed in the analysis.

In step 2, of hierarchical regression for instrumental coping shows that, gender of adolescent accounted for $10 \%$ of the variance in instrumental coping. Step 3, shows that the interaction of gender of adolescent with three parenting styles (responsiveness, demandingness, and autonomy granting) respectively accounted for 19\% of variance in instrumental coping strategy. A significant interaction effect of parental demandingness $\mathrm{x}$ gender of adolescent was noticed $(\beta=-.263, \mathrm{p}<.001)$. The contribution of is parental demandingness $\mathrm{x}$ gender of adolescent is most in the second step as revealed from the $\mathrm{sr}^{2}=.271$. Two explore the interaction effect more 
interaction plot was formed with the help of Modgraph-I, (Jose, 2013). The interaction effect in Figure 2, conveys, that high paternal demandingness is moderately associated with instrumental coping strategy for females than male adolescents (Simple Slopes for the comparison group: Female $=0.344, \mathrm{p}<.05$; Simple Slope for the dummy coded group: Male $=-0.342, \mathrm{p}>.05$ ).

3.2.3 Family Structure

For each hierarchical multiple regression for three coping strategies shows no main effect of the moderator, or significant interaction effect of each of the three paternal parenting styles (responsiveness, demandingness, and autonomy granting) with family structure for separate regressions for coping strategies (Table. 4).

Table 3. A hierarchical multiple regression analysis predicting proactive, preventive, instrumental coping strategy from perceived paternal styles (responsiveness, demandingness, and autonomy granting), income of father and their interactions $(\mathrm{N}=180)$

\begin{tabular}{|c|c|c|c|c|c|c|c|c|}
\hline Variable & $\mathrm{B}$ & SE & $\beta$ & $\mathrm{sr}^{2}$ & $\mathrm{R}$ & $\mathrm{R}^{2}$ & $\Delta \mathrm{R}^{2}$ & $\Delta \mathrm{F}(\mathrm{dfs})$ \\
\hline \multicolumn{9}{|l|}{ Proactive coping } \\
\hline Step 1 & & & & & .207 & .043 & .026 & $2.622(3,176)^{*}$ \\
\hline Responsiveness (R) & .277 & .107 & $.202^{* *}$ & .192 & & & & \\
\hline Demandingness (D) & .005 & .094 & .004 & .004 & & & & \\
\hline Autonomy Granting (A) & -.179 & .108 & -.130 & -.072 & & & & \\
\hline Step 2 & & & & & .249 & .062 & .019 & $3.552(1,175)$ \\
\hline Income of father & -.604 & .321 & -.141 & -.130 & & & & \\
\hline Step 3 & & & & & .328 & .108 & .046 & $2.948(3,172)$ \\
\hline $\mathrm{R} \times$ Income of father & .194 & .104 & .142 & .141 & & & & \\
\hline D $x$ Income of father & -.172 & .096 & -132 & -.135 & & & & \\
\hline A x Income of father & -.258 & .107 & -.186 & -.181 & & & & \\
\hline \multicolumn{9}{|l|}{ Preventive coping } \\
\hline Step 1 & & & & & .302 & .091 & .076 & $5.887(3,176)^{* * *}$ \\
\hline Responsiveness (R) & .046 & .107 & .032 & .032 & & & & \\
\hline Demandingness (D) & .285 & .094 & $.221^{* *}$ & .222 & & & & \\
\hline Autonomy Granting (A) & .315 & .108 & $.222^{* *}$ & .214 & & & & \\
\hline Step 2 & & & & & .337 & .114 & .139 & $4.425(1,175)^{*}$ \\
\hline Income of father & -.674 & .320 & $-.153^{*}$ & -.157 & & & & \\
\hline Step 3 & & & & & .416 & .173 & .139 & $4.110(3,172)^{* *}$ \\
\hline $\mathrm{R} x$ Income of father & -.137 & .103 & -.097 & -.100 & & & & \\
\hline D x Income of father & -.275 & .095 & $-.213^{* *}$ & -.216 & & & & \\
\hline A x Income of father & -.098 & .106 & -.068 & -.070 & & & & \\
\hline \multicolumn{9}{|l|}{ Instrumental coping } \\
\hline Step 1 & & & & & .329 & .108 & .093 & $7.133(3,176)^{* * *}$ \\
\hline Responsiveness (R) & .115 & .105 & .082 & .082 & & & & \\
\hline Demandingness (D) & .245 & .093 & $.191^{* *}$ & .195 & & & & \\
\hline Autonomy Granting (A) & .355 & .106 & $.252^{* * *}$ & .244 & & & & \\
\hline Step 2 & & & & & .342 & .117 & .097 & $1.726(1,175)$ \\
\hline Income of father & .417 & .317 & .095 & .099 & & & & \\
\hline Step 3 & & & & & .389 & .151 & .117 & $2.311(3,172)$ \\
\hline $\mathrm{R} x$ Income of father & -.182 & .104 & -.130 & -.123 & & & & \\
\hline D x Income of father & .002 & .096 & .002 & .002 & & & & \\
\hline A $x$ Income of father & -.145 & .106 & -.102 & -.096 & & & & \\
\hline
\end{tabular}

Note. ${ }^{*} \mathrm{p}<.05 ; * * \mathrm{p}<.005 ; * * * \mathrm{p}<.001$ 
Table 4. A Hierarchical Multiple Regression Analysis Predicting Proactive, Preventive, Instrumental coping strategy from Perceived Paternal Styles (Responsiveness, Demandingness, and Autonomy granting), Family Structure and Their Interactions $(\mathrm{N}=180)$

\begin{tabular}{|c|c|c|c|c|c|c|c|c|}
\hline Variable & $\mathrm{B}$ & SE & $\beta$ & $\mathrm{sr}^{2}$ & $\mathrm{R}$ & $\mathrm{R}^{2}$ & $\Delta \mathrm{R}^{2}$ & $\Delta \mathrm{F}(\mathrm{dfs})$ \\
\hline \multicolumn{9}{|l|}{ Proactive coping } \\
\hline Step 1 & & & & & .207 & .043 & .026 & $2.622(3,176)^{*}$ \\
\hline Responsiveness (R) & .277 & .107 & $.202^{* *}$ & .192 & & & & \\
\hline Demandingness (D) & .005 & .094 & .004 & .004 & & & & \\
\hline Autonomy Granting (A) & -.179 & .108 & -.130 & -.124 & & & & \\
\hline Step 2 & & & & & .211 & .045 & .023 & $.336(1,175)$ \\
\hline Family structure & .444 & .766 & .044 & .044 & & & & \\
\hline Step 3 & & & & & .238 & .057 & .018 & $.742(3,172)$ \\
\hline $\mathrm{R} \times$ Family structure & -.053 & .269 & -.016 & -.015 & & & & \\
\hline D x Family structure & -.354 & .280 & -.103 & -.096 & & & & \\
\hline A x Family structure & -.243 & .264 & -.072 & -.070 & & & & \\
\hline \multicolumn{9}{|l|}{ Preventive coping } \\
\hline Step 1 & & & & & .302 & .091 & .076 & $5.887(3,176)^{* * *}$ \\
\hline Responsiveness (R) & .046 & .107 & .032 & .032 & & & & \\
\hline Demandingness (D) & .285 & .094 & $.221^{* *}$ & .222 & & & & \\
\hline Autonomy Granting (A) & .315 & .108 & $.222^{* *}$ & .214 & & & & \\
\hline Step 2 & & & & & .327 & .107 & .087 & $3.117(1,175)$ \\
\hline Family structure & 1.345 & .762 & .128 & .132 & & & & \\
\hline Step 3 & & & & & .350 & .123 & .087 & $1.015(3,172)$ \\
\hline $\mathrm{R} \times$ Family structure & .179 & .267 & .051 & .051 & & & & \\
\hline D x Family structure & -.123 & .278 & .035 & -.034 & & & & \\
\hline A x Family structure & -.451 & .262 & -.130 & -.130 & & & & \\
\hline \multicolumn{9}{|l|}{ Instrumental coping } \\
\hline Step 1 & & & & & .329 & .108 & .093 & $7.133(3,176)^{* * *}$ \\
\hline Responsiveness (R) & .115 & .105 & .082 & .082 & & & & \\
\hline Demandingness (D) & .245 & .093 & $.191^{* *}$ & .195 & & & & \\
\hline Autonomy Granting (A) & .355 & .106 & $.252^{* *}$ & .244 & & & & \\
\hline Step 2 & & & & & .335 & .112 & .092 & $.803(1.175)$ \\
\hline Family structure & .675 & .754 & .065 & .068 & & & & \\
\hline Step 3 & & & & & .357 & .127 & .092 & $.981(3,172)$ \\
\hline R x Family structure & .224 & .264 & .064 & .064 & & & & \\
\hline D x Family structure & -.347 & .275 & -.099 & -.096 & & & & \\
\hline A x Family structure & .031 & .260 & .009 & .009 & & & & \\
\hline
\end{tabular}


Table 5. A Hierarchical Multiple Regression Analysis Predicting Proactive, Preventive, Instrumental coping strategy from Perceived Paternal Styles (Responsiveness, Demandingness, and Autonomy granting), Gender of Adolescent and Their Interactions $(\mathrm{N}=180)$

\begin{tabular}{|c|c|c|c|c|c|c|c|c|}
\hline Variable & $\mathrm{B}$ & SE & $\beta$ & $s r^{2}$ & $\mathrm{R}$ & $\mathrm{R}^{2}$ & $\Delta \mathrm{R}^{2}$ & $\Delta \mathrm{F}(\mathrm{dfs})$ \\
\hline \multicolumn{9}{|l|}{ Proactive coping } \\
\hline Step 1 & & & & & .207 & .043 & .026 & $2.622(3,176)^{*}$ \\
\hline Responsiveness (R) & .277 & .107 & $.202^{* *}$ & .192 & & & & \\
\hline Demandingness (D) & .005 & .094 & .004 & .004 & & & & \\
\hline Autonomy Granting (A) & -.179 & .108 & -.130 & -.124 & & & & \\
\hline Step 2 & & & & & .208 & .043 & .021 & $.066(1,175)$ \\
\hline Gender of adolescent & .167 & .651 & -.019 & .019 & & & & \\
\hline Step 3 & & & & & .306 & .094 & .057 & $.025(3,172)$ \\
\hline $\mathrm{R} \times$ Gender of adolescent & -.492 & .227 & -.174 & -.163 & & & & \\
\hline $\mathrm{D} \times$ Gender of adolescent & .181 & .194 & .071 & .071 & & & & \\
\hline A x Gender of adolescent & -.376 & .226 & -.133 & -.126 & & & & \\
\hline \multicolumn{9}{|l|}{ Preventive coping } \\
\hline Step 1 & & & & & .302 & .091 & .076 & $5.887(3,176)^{* * *}$ \\
\hline Responsiveness (R) & .046 & .107 & .032 & .032 & & & & \\
\hline Demandingness (D) & .285 & .094 & $.221^{* *}$ & .222 & & & & \\
\hline Autonomy Granting (A) & .315 & .108 & $.222^{* *}$ & .214 & & & & \\
\hline Step 2 & & & & & .306 & .094 & .073 & $.476(1,175)$ \\
\hline Gender of adolescent & -.450 & .652 & -.051 & -.052 & & & & \\
\hline Step 3 & & & & & .362 & .131 & .096 & $2.472(3,172)$ \\
\hline $\mathrm{R} \times$ Gender of adolescent & -.280 & .229 & -.096 & -.093 & & & & \\
\hline D x Gender of adolescent & -.399 & .195 & -.152 & -.154 & & & & \\
\hline A x Gender of adolescent & -.128 & .228 & -.044 & -.043 & & & & \\
\hline \multicolumn{9}{|l|}{ Instrumental coping } \\
\hline Step 1 & & & & & .329 & .108 & .093 & $7.133(3,176)^{* * *}$ \\
\hline Responsiveness (R) & .115 & .105 & .082 & .082 & & & & \\
\hline Demandingness (D) & .245 & .093 & $.191^{* *}$ & .195 & & & & \\
\hline Autonomy Granting (A) & .355 & .106 & $.252^{* * *}$ & .244 & & & & \\
\hline Step 2 & & & & & .330 & .109 & .089 & $.139(1,175)$ \\
\hline Gender of adolescent & .239 & .641 & .027 & .028 & & & & \\
\hline Step 3 & & & & & .445 & .198 & .166 & $6.370(3,172)^{* * *}$ \\
\hline $\mathrm{R} \times$ Gender of adolescent & -.061 & .218 & -.021 & -.022 & & & & \\
\hline D x Gender of adolescent & -.686 & .186 & $-.263^{* * *}$ & -.271 & & & & \\
\hline A x Gender of adolescent & -.485 & .217 & -.168 & -.168 & & & & \\
\hline
\end{tabular}

Note. ${ }^{*} \mathrm{p}<.05 ; * * \mathrm{p}<.005 ; * * * \mathrm{p}<.001$ 


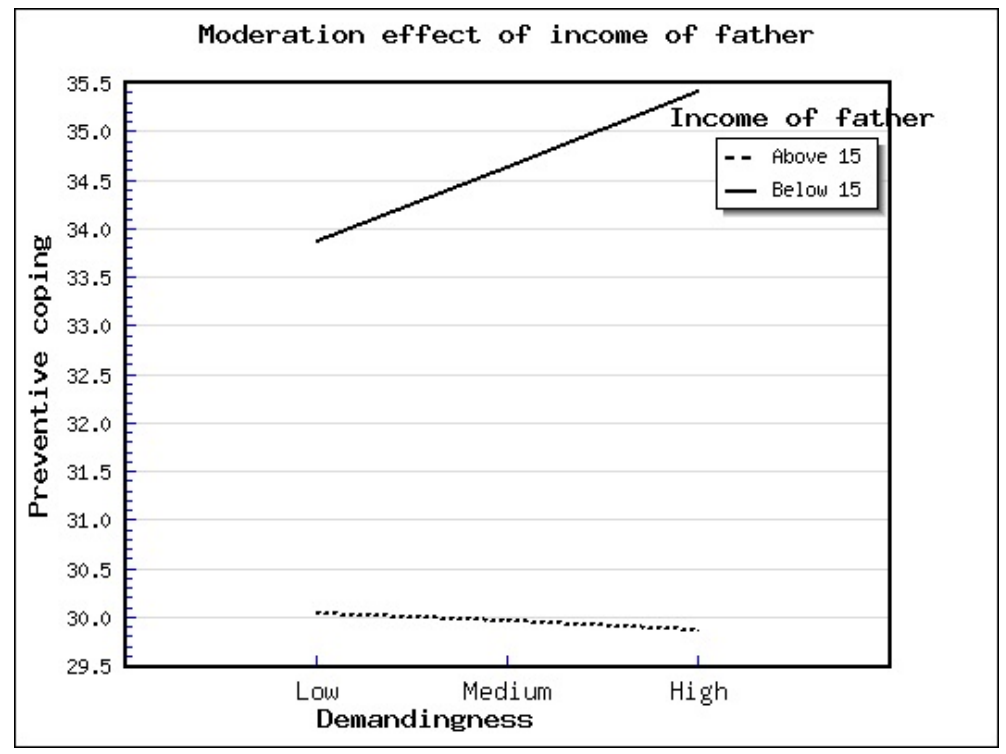

Figure 1. Moderation of the effect of paternal demandingness on preventive coping by income of father

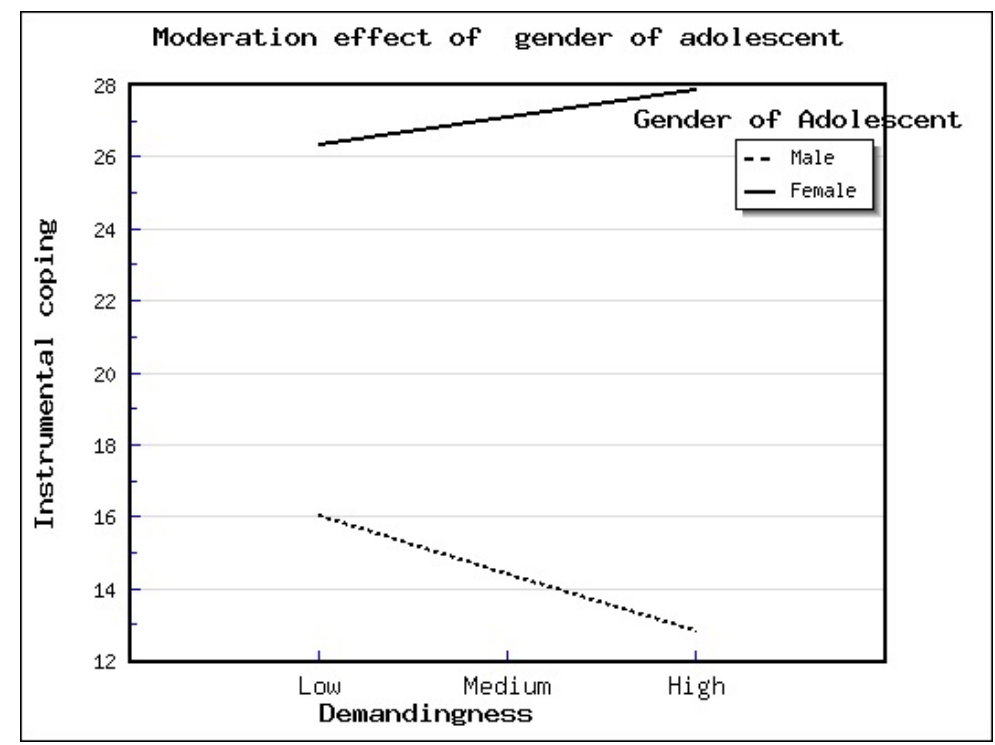

Figure 2. Moderation of the effect of paternal demandingness on instrumental coping by gender of adolescent

\section{Discussion}

Adolescents' perception of paternal demandingness was found to positively predict preventive and instrumental coping strategy in adolescents. Lin and Lian (2011), remark about Asian fathers that strict disciplinarian fathers as well can show receptiveness and understanding towards their children. Thus it is no surprise to find Indian children of demanding fathers healthy to use healthy coping strategies. Several studies from all over the world specifically from China (Chao, 2001; Leung, Lau, \& Lam, 1998), Korea (Rohner \& Pettengill, 1985), Turkey (Kagitcibasi, 2005), Pakistan (Stewart, Bond, Kennard, Ho, \& Zaman, 2002), Algeria, Saudi Arabia (Dwairi \& Achoui, 2010) and on African American community(McWayne, Owsianik, Green, \& Fantuzzo, 2008; Randolph, 1995); suggests that parenting styles which delimits autonomy of children were found to have no negative influence on psychological adjustment of children's (Manzi, Regalia, Pelucchi, \& Fincham, 2012).

Adolescents' perception of paternal responsiveness again was found to significantly predict strategic coping in adolescents. Recent investigation suggests that middle class fathers in urban areas of India are turning out to be more affectionate, and nurturing towards their children, pointing to a cultural shift (Roopnarine, Talukder, Jain, 
Joshi, \& Srivastav, 1990). Moreover, previous studies support the fact that autonomy granting parenting style leads to healthier outcomes in adolescents. A striking feature of the study was the finding that, adolescents' perception of paternal autonomy granting predicts preventive and instrumental coping strategy in adolescents. In support of our findings, it can be reported that autonomy granting parenting has a wide spectrum of healthier child outcomes, as academic achievement, psychological wellbeing and health socially adaptive behaviour (Gray \& Steinberg, 1999). Parental autonomy is also found to lead to better adjustment and higher levels of psychosocial functioning (Deci \& Ryan, 2000). Hence our study finding of paternal autonomy predicting two important proactive coping strategies is not out of context.

Income of father was found to moderate the relationship between paternal demandingness and preventive coping strategy. Higher level of perceived paternal demandingness by adolescents of low income fathers reported higher preventive coping strategy in the study. On the other hand, gender of adolescent found to moderate significantly the relationship between paternal demandingness and instrumental coping strategy than male adolescents. Li et al (2002) indicate in their study findings that parents from lower socio-economic status were more restrictive, emphasized more dominance and conformity in comparison to higher socio-economic status parents; which determines the concept of parental demandingness in case of lower income level in the present study. One explanation behind lower level of income moderating the relationship between responsiveness of father and preventive coping may be that lesser availability of resource make people cautious instead of being indulgent (Seymour, 1999). On the other hand, paternal demandingness on the wake of recent perpetrations against women's safety can be a probable reason, why female adolescents report higher paternal demandingness. Besides, recent studies also support the concept of Indian paternal demandingness on the grounds that, Indian fathers are habitually more protective towards girl child than their male children (Manhas \& Kour, 2014). Adolescents' perception of Indian paternal demandingness is rationalized further as a function of fewer verbal transactions between father and child. Lesser frequency of verbalization by fathers and more emphasis on imposing consequences rather than verbal reconciliation are stated in a new study as the probable reasons behind adolescents' perception of their fathers as demanding (D'souza \& Mendes, 2014). On the whole, perpetual notion of collectivism and authority in Indian tradition fosters an environment to thrive which clarifies the significant relationship between perceived paternal demandingness and instrumental coping moderated by gender of adolescent.

\section{Conclusion and Limitation of the Study}

Quite a significant number of studies have been conducted in South Asian regions to explore more about the intricacies of parenting practices. The present study shows that Indian fathers are increasingly sharing an important equation in parenting. More of Indian fathers are opting traditional demandingness with autonomy as parenting practice, instead of the strict disciplinarian attitude commonly seen. Thomas Kulanjiyil (2012) in support of traditional Indian parenting remarks that despite the emphasis on control is asserted more, traditional Indian parenting has several positive aspects as well. Interdependence of culture in terms of community living, positive personality development in terms of modesty and chastity are not only significant positive aspects, these also promise unique identity among immigrating Indians abroad (Kulanjjyil, 2012). The present study provides a glimpse in to the transforming face of parenting practices in India and its impact on development positive coping ability among adolescents. The study provides a new appeal in terms of new emergence of parenting style out of assimilation of new and old traditions in parenting practices. Indian parents are increasingly encouraging autonomy and adopting individualistic orientation parent-child transaction thereby contributing to greater self-reliance and adaptation among their children in the new globalized cultural interface (Saraswath \& Ganapathy, 2002). Saraswath and Ganapathy (2002) rightly noted that the traditional nuclear urbanized families are giving way to parents who are less authoritarian, more autonomy granting, and responsive to their children's need. The changing face of Indian parenting with its unique assimilation of traditional and new appears promising when it comes to children's capacity development.

Owing to insufficient sample size structural equation modelling could not be conducted for model testing. Certain important variable likes, birth order of adolescents, mother tongue, parent's education and employment status of parents could not be used in the study to analyse their probable impact.

Future research could explore more how to develop effective ways of child rearing; an instance might "competent parenting" suggested by Belsky, Robins, and Gamble (1984). Parent education program could be developed for both urban as well as rural population in India to bring about the best in children. 


\section{Acknowledgements}

We sincerely acknowledge the valuable comments received from the reviewers of our paper. This has really helped us in improving the quality of the paper.

\section{References}

Afshartous, D., \& Preston, R. A. (2011). Key Results of Interaction Models with Centering. Journal of Statistics Education, 11(3), 1-24. Retrieved from http://www.amstat.org/publications/jse/v19n3/afshartous.pdf

Aiken, L., \& West, S. (1991). Multiple Regression: Testing and interpreting interactions. Thousand Oaks, California: Sage Publications Ltd.

Akhtar, Z. (2012). The Effect of Parenting Style of Parents on the Attachment Styles of Undergraduate Students. Language in India, 12 (1), 555-566. Retrieved from http://www.languageinindia.com/jan2012/ zarinaparenting.pdf

Aspinwall, L. G., \& Taylor, S. E. (1997). A stitch in time: Self-regulation and proactive coping. Psychological Bulletin, 121(3), 417-436. http://dx.doi.org/10.1037/0033-2909.121.3.417

Barnow, S. et al. (2004). The relation of a family history of alcoholism, obstetric complications and family environment to behavioral problems among 154 adolescents in Germany: Results from the children of alcoholics study in Pomerania. European Addiction Research, 10(1), 8-14. http://dx.doi.org/10.1159/ 000073721

Baron, R. M., \& Kenny, D. A. (1986). The moderator-mediator variable distinction in social psychological research: Conceptual, strategic, and statistical considerations. Journal of Personality and Social Psychology, 51(6), 1173-1182. http://dx.doi.org/10.1037/0022-3514.51.6.1173

Baumrind, D. (1991). The influence of parenting style on adolescent competence and substance abuse. Journal of Early Adolescence, 11(1), 56-95. http://dx.doi.org/10.1177/0272431691111004

Belsky, J., Robins, E., \& Gamble, W. (1984). The determinants of parental competence: Toward a contextual theory. In M. Lewis, \& L. Rosenblum (Eds.), Beyond the Dyad: Social Connections (pp. 251-279). NY: Plenum. http://dx.doi.org/10.1007/978-1-4757-9415-1_11

Bhat, A., \& Aminabhavi, V. (2011). Home Environment and Psychosocial competence of Adolescents. Journal of Psychology, 2(1), 57-63. Retrieved from http://www.krepublishers.com/02-Journals/JP

Chadda, R. K., \& Deb, K. S. (2013). Indian family systems, collectivistic society and psychotherapy. Indian Journal of Psychiatry, 55(6), 299-309. http://dx.doi.org/10.4103/0019-5545.105555

Chao, R. (1994). Beyond parental control and authoritarian parenting style: Understanding Chinese Parenting through the cultural notion of training. Child Development, 65(4), 1111-1119. http://dx.doi.org/10.2307/ 1131308

Chao, R. K. (2001). Extending research on the consequences of parenting style for Chinese Americans and European Americans. Child Development, 72(6), 1832-1843. http://dx.doi.org/10.1111/1467-8624.00381

Chao, R., \& Tseng, V. (2002). Parenting of Asians. In M. H. Bornstein (Eds), Handbook of parenting: Social conditions and applied parenting. Mahwah, New Jersey: Lawrence Erlbaum Associates.

Cohen, S., \& Wills, T. A. (1985). Stress, social support, and the buffering hypothesis. Psychological Bulletin, 98(2), 310-357. http://dx.doi.org/10.1037/0033-2909.98.2.310

Compas, B. E., Banez, G. E., Malcarne, V., \& Worsham, N. (1991). Perceived control and coping with stress: A developmental perspective. Journal of Social Issues, 47(4), 23-34. http://dx.doi.org/10.1111/ j.1540-4560.1991.tb01832.x

D'Cruz, P., \& Bharat, S. (2001). Beyond Joint and Nuclear: The Indian Family Revisited. Journal of Comparative Family Studies, 32(2), 167-94. Retrieved from http://connection.ebscohost.com/c/articles/ 4536398/beyond-joint-nuclear-indian-family-revisited

D'souza, G., \& Mendes, J. (2014). A Comparative Study of the Two Dimensions of Parenting Style and their Effects on the Self-Concept of Pre-Adolescents. The International Journal of Indian Psychology, 2(1), 24-34. Retrieved from http://www.academia.edu/11116844

Darling, N., \& Steinberg, L. (1993). Parenting style as context: An integrative model. Psychological Bulletin, 113(3), 487-496. http://dx.doi.org/10.1037/0033-2909.113.3.487 
Darling, N., \& Toyokawa, T. (1997). Construction and validation of the Parenting Style Inventory II. The Pennsylvania State University: Internal publication. Rerieved from http://www.oberlin.edu/faculty/ ndarling/lab/psiii.pdf

Dasgupta, M. (1987). Discrimination Against Female Children in Rural Punjab, India. Population and Development Review, 13(1), 77-100. http://dx.doi.org/10.2307/1972121

Deci, E. L., \& Ryan, R. M. (2000). The "what" and "why" of goal pursuits: Human needs and the self-determination of behavior. Psychological Inquiry, 11(4), 227-268. http://dx.doi.org/10.1207/ S15327965PLI1104_01

Deci, E. L., Vallerand, R. U., Pelletier, L. G., \& Ryan, R. M. (1991). Motivation and education: The self determination perspective. Educational psychologist, 26(3/4), 325-346. http://dx.doi.org/10.1080/ 00461520.1991 .9653137

Dsouza, J. F., \& Paul, P. (2013). Perceived Paternal Parenting Style and Social Competence. Journal of the Indian Academy of Applied Psychology, 39(1), 103-109. Retrieved from http://medind.nic.in/jak/t13/i1/ jakt13i1p103.pdf

Dusek, J. B., \& Danko, M. (1994). Adolescent coping styles and perceptions of parental child rearing. Journal of Adolescent Research, 9(4), 412-426. http://dx.doi.org/10.1177/074355489494002

Dwairy, M., \& Achoui, M. (2010). Parental control: A second cross-cultural research on parenting and psychological adjustment of children. Journal of Child and Family Studies, 19(1), 16-22. http://dx.doi.org/10.1007/s10826-009-9334-2

Field, A. (2013). Discovering Statistics using IBM SPSS Statistics (4th ed.). Thousand Oaks, California: Sage Publications Ltd.

Galy, M. (2007). The relationship between family environment, parenting styles and adolescents' well-being in Cameroon (Unpublished doctoral dissertation). University Putra Malaysia, Malaysia.

Gray, M. R., \& Steinberg, L. (1999). Unpacking authoritative parenting: Reassessing a multidimensional construct. Journal of Marriage and the Family, 61(3), 574-587. http://dx.doi.org/10.2307/353561

Greenglass, E. R., Schwarzer, R., \& Taubert, S. (1999). The proactive coping inventory (PCI): A multidimensional research instrument. Retrieved from http://www.psych.yorku.ca/greenglass

Isaac, R., Annie, I. K., \& Prashanth, H. R. (2014). Parenting in India. In H. Selin (Ed.), Parenting Across Cultures Childrearing, Motherhood and Fatherhood in Non-Western Cultures: Science Across Cultures: The History of Non-Western Science. http://dx.doi.org/10.1007/978-94-007-7503-9_4

Jambunathan, S., \& Counselman, K. (2002). Parenting attitudes of Asian Indian mothers living in the United States and in India. Early Child Development and Care, 172(6), 657-662. http://dx.doi.org/10.1080/ 03004430215102

Jose, P. E. (2013). ModGraph-I: A programme to compute cell means for the graphical display of moderational analyses (The internet version, Version 3.0). Victoria University of Wellington, Wellington, New Zealand. Retrieved from http://pavlov.psyc.vuw.ac.nz/paul-jose/modgraph

Kadhiravan, S., \& Kumar, K. (2012). Enhancing Stress Coping Skills among College Students. Researchers World. Journal of Arts, Science and Commerce, 4(1), 49-55. Retrieved from http://www.researchersworld.com/vol3/issue4/vol3_issue4_1/Paper_07.pdf

Kagitcibasi, C. (2005). Autonomy and Relatedness in Cultural Context. Implications for Self and Family. Journal of Cross-Cultural Psychology, 36(4), 403-422. http://dx.doi.org/10.1177/0022022105275959

Kakar, S. (1978). The Inner World: A Psycho-Analytic Study of Childhood and Society in India. New York: Oxford University Press.

Keshavarza, S., \& Baharudina, R. (2012). The moderating role of gender on the relationships between perceived paternal parenting style, locus of control and self-efficacy. Procedia-Social and Behavioral Sciences, 32, 63-68. http://dx.doi.org/10.1016/j.sbspro.2012.01.011

Kulanjiyil, T. (2012). Traditional Indian parenting practices. Family Matters. India Tribune. Retrieved from http://www.indiatribune.com.traditional-indian-parenting-practices\&catid=99:column\&Itemid=462 
Lakshmi, A. R., \& Arora, M. (2006). Perceived Parental Behaviour as Related to Student's Academic School Success and Competence. Journal of the Indian Academy of Applied Psychology, 32(1), 47-52. Retrieved from http://medind.nic.in/jak/t06/i1/jakt06ilp53.pdf

Lazarus, R. S., \& Folkman, S. (1984). Stress, appraisal, and coping. New York: Springer.

Leung, K., Lau, S., \& Lam, W. (1998). Parenting styles and academic achievement: A cross-cultural study. Merrill-Palmer Quarterly, 44(2), 157-172. Retrieved from http://www.jstor.org/discover/10.2307

Lewis-Beck, M. S., Bryman, A., \& Liao, T. F. (2004). The Sage Encyclopedia of Social Science Research Methods. Sage, Thousand Oaks. http://dx.doi.org/10.4135/9781412950589

Li, Y. et al. (2002). Maternal children behaviors and correlates in rural minority areas of Yannan, China. Developmental and Behavioral Pediatrics, 21(2), 114-122. http://dx.doi.org/10.1097/00004703-200004 000-00005

Lin, T. E., \& Lian, T. C. (2011). Relationship between Perceived Parenting Styles and Coping Capability among Malaysian Secondary School Students. Proceedings of International Conference on Social Sciences in Singapore. Retrieved from http://www.ipedr.com/vol5/no1/5-H00032.pdf

Manhas, S., \& Kour, G. (2014). Perceived Parenting During Adolescence in Context of Parents' and Adolescents' Sex. Indian Journal of Applied Research, 4(8), 314-331. http://dx.doi.org/10.15373/ 2249555X/August2014/79

Manzi, C., Regalia, C., Pelucchi, S., \& Fincham, F. D. (2012). Documenting different domains of promotion of autonomy in families. Journal of Adolescence, 35(2), 289-98. http://dx.doi.org/10.1016/ j.adolescence.2011.10.011

Mason, C. A., Walker-Barnes, C. J., Tu, S., Simons, J., \& Martinez-Arrue, R. (2004). Ethnic differences in the affective meaning of parental control behaviors. Journal of Primary Prevention, 25(1), 59-79. http://dx.doi.org/10.1023/B:JOPP.0000039939.83804.37

McWayne, C. M., Owsianik, M., Green, L. E., \& Fantuzzo, J. W. (2008). Parenting behaviors and preschool children's social and emotional skills: A question of the consequential validity of traditional parenting constructs for low-income African Americans. Early Childhood Research Quarterly, 23(2), 173-192. http://dx.doi.org/10.1016/j.ecresq.2008.01.001

Meteyer, K. B., \& Jenkins, M. (2009). Dyadic parenting and children's externalizing symptoms. Family Relations, 58(3), 289-302. http://dx.doi.org/10.1111/j.1741-3729.2009.00553.x

Natarajan, A. (2010). Culture and Perceived Parenting Style: Implications For Interpersonal And Academic Functioning In Indian And American College Students. (Doctoral Dissertation). Retrieved from https://etd.ohiolink.edu/

Rai, R. N., Pandey, R. C., \& Kumar, K. (2009). Perceived Parental Rearing Style and Personality among Khasi Adolescents. Journal of the Indian Academy of Applied Psychology, 35, 57-60. Retrieved from http://medind.nic.in/jak/t09/s1/jakt09s1p57.pdf

Roopnarine, J. L., Talukder, E., Jain, D., Joshi, P., \& Srivastav, P. (1990). Characteristics of holding, patterns of play, and social behaviors between parents and infants in New Delhi, India. Developmental Psychology, 26(4), 667-673. http://dx.doi.org/10.1037/0012-1649.26.4.667

Rose, G. M., Dalakas, V., \& Kropp, F. (2003). Consumer socialization and parental style across cultures: Findings from Australia, Greece, and India. Journal of Consumer Psychology, 13(4), 366-376. http://dx.doi.org/10.1207/S15327663JCP1304_04

Saraswathi, T. S., \& Ganapathy, H. (2002). Indian parents' ethnotheories as reflections of the Hindu scheme of child and human development. In H. Keller, \& Y. H. Poortinga (Eds.), Between culture and biology: Perspectives on ontogenetic development (pp. 79-88). New York, NY, US: Cambridge University Press. http://dx.doi.org/10.1017/CBO9780511489853.005

Schwarzer, R., \& Knoll, N. (2003). Positive coping: Mastering demands and searching for meaning. In S. J. Lopez, \& C. R. Snyder (Eds.), Positive psychological assessment: A handbook of models and measures (pp. 393-409). Washington, D. C: American Psychological Association. http://dx.doi.org/10.1037/10612-025

Schwarzer, R., \& Taubert, S. (2002). Tenacious goal pursuits and striving toward personal growth: Proactive coping. In E. Frydenberg (Ed.), Beyond coping: Meeting goals, visions and challenges (pp.19-35). London: Oxford University Press. 
Seymour, S. (1999). Women, family, and child care in India: A world in transition. New York: Cambridge University Press.

Shalini, A., \& Acharya, Y. T. (2013). Perceived Paternal Parenting style on Emotional Intelligence of Adolescents. Guru Journal of Behavioral and Social Sciences, 1(4), 194-202.

Sharma, M., Sharma, N., \& Yadava, A. (2011). Parenting styles and Depression among adolescents. Journal of the Indian Academy of Applied Psychology, 37(1), 60-68. Retrieved from http://medind.nic.in/jak/t11/i1/ jakt11ilp60.pdf

Spera, C. (2005). A Review of the Relationship Among Parenting Practices, Parenting Styles, and Adolescent School Achievement. Educational Psychology Review, 17(2), 125-146. http://dx.doi.org/10.1007/ s10648-005-3950-1

Stewart, S. M., Bond, M. H., Kennard, B. D., Ho, L. M., \& Zaman, R. M. (2002). Does the Chinese construct of guan export to the West? International Journal of Psychology, 37(2), 74-82. http://dx.doi.org/10.1080/ 00207590143000162

Terry, D. J. (2004). Investigating the relationship between parenting styles and delinquent behavior. McNair Scholars Journal, 8(1). Retrieved from http://scholarworks.gvsu.edu/mcnair/vol8/iss1/11

Thergaonkar, N., \& Wadekar, A. J. (2007). Relationship between Test Anxiety and Parenting Style. Journal of Indian Association for Child and Adolescent Mental Health, 2(4), 10-12. Retrieved from http://files.eric.ed.gov/fulltext/EJ896856.pdf

Verma, S., \& Sharma, D. (2006). Cultural dynamics of family relations among Indian adolescence in Varied contexts. In K. H. Rubin (Ed.), Parental beliefs, parenting, and child development in cross-cultural perspective. New York: Psychology Press.

Wei, M. et al. (2008). Moderating effects of three coping strategies and self-esteem on perceived discrimination and depressive symptoms: A minority stress model for Asian international students. Journal of Counseling Psychology, 55(4), 451-462. http://dx.doi.org/10.1037/a0012511

Wolfradt, U., Hempel, S., \& Miles, J. N. V. (2003). Perceived parenting styles, depersonalisation, anxiety and coping behaviour in adolescents. Perceived parenting styles, depersonalisation, anxiety and coping behaviour in adolescents. Personality and Individual Differences, 34(3), 521-532. http://dx.doi.org/ $10.1016 / \mathrm{s} 0191-8869(02) 00092-2$

\section{Copyrights}

Copyright for this article is retained by the author(s), with first publication rights granted to the journal.

This is an open-access article distributed under the terms and conditions of the Creative Commons Attribution license (http://creativecommons.org/licenses/by/3.0/). 